Article

\title{
Variable-Frequency Ultrasonic Treatment on Microstructure and Mechanical Properties of ZK60 Alloy during Large Diameter Semi-Continuous Casting
}

\author{
Xingrui Chen, Qichi Le *, Xibo Wang, Qiyu Liao and Chaoyang Chu \\ Key Lab of Electromagnetic Processing of Materials, Ministry of Education, Northeastern University, \\ 314 Mailbox, Shenyang 110819, China; neuchenxr@163.com (X.C.); xbwang525@163.com (X.W.); \\ liao539524290@163.com (Q.L.); nxpycxr@gmail.com (C.C.) \\ * Correspondence: qichil@mail.neu.edu.cn; Tel.: +86-24-8368-3312 \\ Academic Editor: Manoj Gupta \\ Received: 7 April 2017; Accepted: 4 May 2017; Published: 16 May 2017
}

\begin{abstract}
Traditional fixed-frequency ultrasonic technology and a variable-frequency ultrasonic technology were applied to refine the as-cast microstructure and improve the mechanical properties of a ZK60 (Mg-Zn-Zr) alloy during large diameter semi-continuous casting. The acoustic field propagation was obtained by numerical simulation. The microstructure of the as-cast samples was characterized by optical and scanning electron microscopy. The variable-frequency ultrasonic technology shows its outstanding ability in grain refinement compared with traditional fixed-ultrasonic technology. The variable-frequency acoustic field promoted the formation of small $\alpha$-Mg globular grains and changed the distribution and morphology of $\beta$-phases throughout the castings. Ultimate tensile strength and elongation are increased to $280 \mathrm{MPa}$ and $8.9 \%$, respectively, which are $19.1 \%$ and $45.9 \%$ higher than the values obtained from billets without ultrasonic treatment and are $11.6 \%$ and $18.7 \%$ higher than fixed-frequency ultrasound treated billets. Different refinement efficiencies appear in different districts of billets attributed to the sound attenuation in melt. The variable-frequency acoustic field improves the refinement effect by enhancing cavitation-enhanced heterogeneous nucleation and dendrite fragmentation effects.
\end{abstract}

Keywords: magnesium alloy; semi-continuous casting; grain refinement; mechanical properties; ultrasonic treatment

\section{Introduction}

Magnesium alloy has a multitude of applications in various domains such as vehicles, aerospace, medicine, computer, communication, and consumer electronics, for its outstanding advantages, including low density, high specific strength and stiffness, positive conductivity, and promising machinability [1-8]. However, it has its own characteristics such as low thermal capacity, melting heat, and thermal conductivity, which can lead to hard heat dissipation and huge temperature difference between solidification interface and the melt center, resulting in coarse grains, developed dendrites, and inhomogeneous structure [9-11]. Nevertheless, refinement grain billets play a significant role in the subsequent deformation process. Consequently, it is indispensable to produce aplitic, homogeneous, pure magnesium alloy billets. Generally, there are two methods to refine grain during solidification process, including chemical stimulation [12-15] and physical induction [16-19]. Chemical elements, such as $\mathrm{Zr}, \mathrm{C}$, and $\mathrm{Ca}$ are added as grain refiners into $\mathrm{Mg}$ alloys and the addition of these grain refiners can effectively refine grain size. However, chemical methods also bring some problems and face a mushrooming number of environmental challenges, for example the addition of iron element 
can lead to low corrosion resistance [20]. Accordingly, the physical method is a favorable option for grain refinement.

A large number of studies show that ultrasound has excellent contributions in degassing [21-23] and grain refinement. Fang et al. suggest that it is possible to obtain non-dendritic and globular $\alpha$-Mg grains by supplying acoustic vibration to molten $\mathrm{Mg}-\mathrm{Zn}-\mathrm{Y}$ alloy [24]. Globular grains were also obtained in AZ91 alloy subject to high intensity ultrasonic vibration [25] demonstrated by Gao et al. Acoustic cavitation and acoustic streaming are two useful effects born in ultrasonic vibration. Eskin has explained the effect of ultrasound on grain refinement: cavitation-enhanced heterogeneous nucleation and dendrite fragmentation [26]. When melt is treated by high intensity ultrasonic vibrations, a multitude of tiny bubbles appear because of acoustic pressure, which start growing, shrinking, and finally collapse following variation of acoustic pressure. Undercooling occurs in the bubble interface during expansion because of energy absorbed from melt, giving rise to nucleation on the bubble surface. High pressure produced by collapses of cavitation bubbles create acoustic streaming in melt, disturbing nuclei into the surrounding liquid, thus promoting heterogeneous nucleation, and this huge pressure leads to fragmentation of dendritic cells in the mushy zone, which are disturbed by acoustic streaming, adding the number of nuclei.

Although grain refinement by ultrasonic vibration technology has succeeded under laboratory conditions, it was rarely used in industrial manufacture. Traditional ultrasonic applications are based on a fixed frequency, well-turned ultrasonic source where a host of design and parameters have to be respected. These basic requirements cannot be satisfied in factories with complex environments. Therefore, the resonance condition of melt cannot be fully satisfied due to variable load conditions. It is a pity that ultrasonic energy as an environmentally friendly and green energy has not been applied in magnesium industrial production. Therefore, in this work, variable-frequency ultrasonic vibration was introduced to ZK60 alloy melt during major diameter semi-continuous casting. Meanwhile, the variable-frequency ultrasonic field propagations in ZK60 alloy melt were calculated by the finite element method. The paper focuses on the effect of grain refinement by variable-frequency and difference between fixed-frequency ultrasound and variable-frequency ultrasound during large diameter semi-continuous casting.

\section{Experimental Procedures}

\subsection{Magnesium Alloy and Experimental Set-Up}

The composition of ZK60 alloy used in this work is shown in Table 1, obtained by an inductively coupled plasma analyzer.

Table 1. Composition of ZK60 alloy used in this work.

\begin{tabular}{cccccccc}
\hline Element & Zn & Zr & Fe & Cu & Si & Ni & Mg \\
\hline wt $\%$ & 5.720 & 0.644 & 0.018 & 0.013 & 0.026 & 0.010 & Balance \\
\hline
\end{tabular}

Figure 1 illustrates the experimental set-up for this study. The ultrasonic vibration system comprises an ultrasonic power supply, an ultrasonic converter with a maximum power output of $3000 \mathrm{~W}$, a $35 \mathrm{~mm}$ diameter and $960 \mathrm{~mm}$ long acoustical wave-guide, and a $35 \mathrm{~mm}$ diameter and $120 \mathrm{~mm}$ long stainless steel acoustic radiator/horn. The ultrasonic power supply unit is linked to a computer, and consequently the ultrasonic frequency and power are fully controlled by dedicated Windows compatible software. This ultrasonic vibration system can supply variable frequency ultrasonic agitation, which has a $20 \mathrm{kHz}$ center frequency, a $200 \mathrm{kHz}$ changing frequency, and a frequency variation range of $\pm 1 \mathrm{kHz}$. An air cooler was utilized to guarantee the ultrasonic system has a favorable working environment. The semi-continuous casting system used in this research includes a crystallizer with a $255 \mathrm{~mm}$ diameter duraluminum inner sleeve, a tundish, a casting control system, a melting 
furnace, and a water cooling system. The supporting and positioning device of the ultrasonic system could achieve three-dimensional position adjustment.

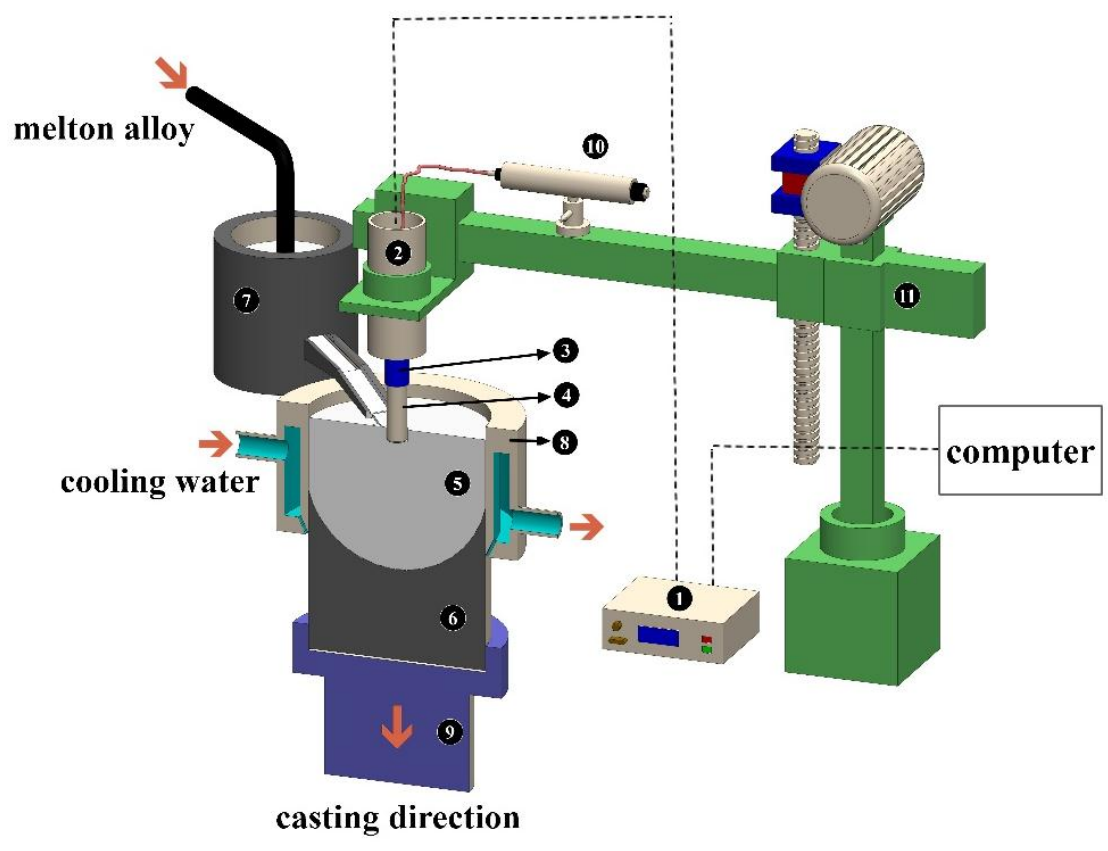

Figure 1. Schematic of the experimental set-up: 1-ultrasonic power supply, 2-ultrasonic converter, 3-acoustical wave-guide, 4-acoustic radiator/horn, 5-liquid melt, 6-billet, 7-tundish, 8-crystallizer, 9-dummy bar head, 10-air cooler, 11-positioning device.

\subsection{Casting Procedure and Samples Characterization}

The melting of ZK60 Mg alloy was carried out in a resistance furnace with an iron crucible containing approximately $100 \mathrm{~kg}$ of metal and protected by $\mathrm{CO}_{2}+0.5 \% \mathrm{SF}_{6}$ atmosphere in order to prevent severe oxidation. The melt was transferred to a tundish from crucible at $710{ }^{\circ} \mathrm{C}$ and then transferred to the crystallizer. The casting started when temperature of melt in the tundish was $660^{\circ} \mathrm{C}$. Cooling water flow was $4.63 \mathrm{t} / \mathrm{h}$. Casting velocity was $50 \mathrm{~mm} / \mathrm{min}$. In the first casting, the billet was cast by conventional direct chilling casting (DC) process. After casting about $600 \mathrm{~mm}$ length, the preheated ultrasonic horn at $660{ }^{\circ} \mathrm{C}$ was inserted $50 \mathrm{~mm}$ under the surface of melting liquid during the casting process. Thus, the melt was treated by ultrasonic vibration with $0 \mathrm{~W}$ (no ultrasonic treatment), fixed-frequency of $20 \mathrm{kHz}$ with $1800 \mathrm{~W}$, and variable-frequency of $20 \pm 1 \mathrm{kHz}$ with $1800 \mathrm{~W}$. The treated billet was cooled to room temperature.

In order to compare the microstructure of each experimental condition, samples were cut at positions shown in Figure 2 from different locations in the cross-section of the billets. The characterizations of microstructure were obtained from a Leica optical microscope and a scanning electronic microscope (SEM). Samples were ground by using 400, 1000, 2000, and $3000 \mathrm{SiC}$ papers, then polished and etched using a solution of $4 \%$ nitric acid in alcohol to reveal their microstructures. The average grain size of the billets was measured by using the mean linear intercept method, and at least 110 intercepts were utilized to get the average grain size value. 


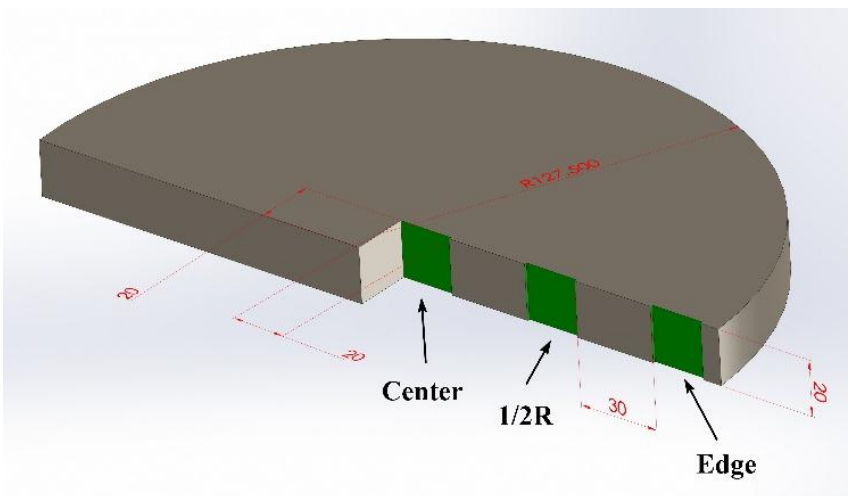

Figure 2. Schematic illustration of the positions of specimen taken from billets.

\subsection{Mechanical Properties Tests and Segregation Rate Detection}

Mechanical properties were characterized by tensile tests at room temperature. Tensile specimens were machined along the longitudinal direction at the position of center, $1 / 2 \mathrm{R}$ and edge of billet with a gage length of $36 \mathrm{~mm}$ and a diameter of $6 \mathrm{~mm}$, as shown in Figure 3b. The initial strain rates were $1 \times 10^{-3} \cdot \mathrm{s}^{-1}$.

Segregation rate detections were carried out by inductively coupled plasma analyzer. Strip samples were cut from billets and the sample tests every $23 \mathrm{~mm}$, as shown in Figure 3a. In this work, the segregation rate was used to judge the segregation, which was obtained as follows.

$$
\eta_{i}=\frac{x_{i}-\sum x_{i} / 11}{\sum x_{i} / 11} \times 100 \%
$$

where $\eta_{i}$ is the segregation rate, $x_{i}$ is the element content at position $i$.

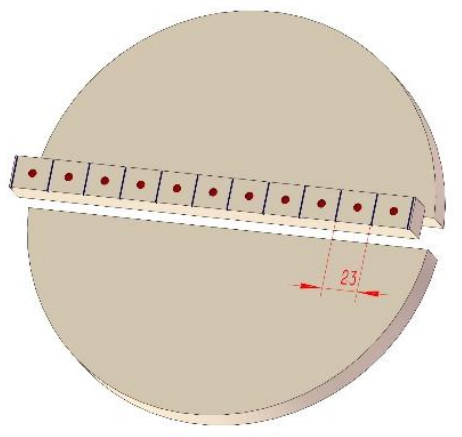

(a)

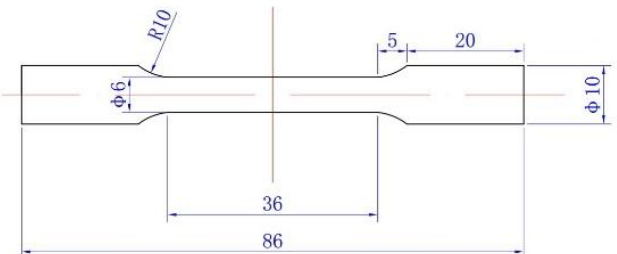

(b)

Figure 3. Schematic illustration of (a) positions of segregation rate detection; (b) tensile samples size.

\section{Results and Discussion}

\subsection{Microstructure Refinement by Different Ultrasonic Treatments}

The microstructures of the as-cast ZK60 alloy without ultrasonic processing are composed of uneven coarse $\alpha-\mathrm{Mg}$ grains, as shown in Figure 4 . The coarse dendrites of the primary phase are presented throughout the whole cross-section of the billets. 

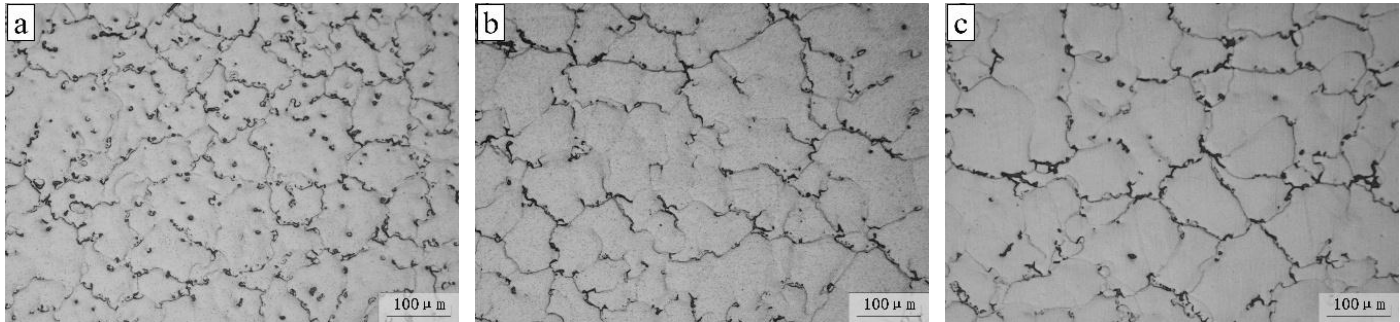

Figure 4. Microstructures of as-cast ZK60 alloy without ultrasonic processing at (a) center; (b) 1/2R;

(c) edge position of billet.

Figure 5 illustrates the as-cast microstructures of the ZK60 alloy isothermally suffered by $20 \mathrm{kHz}$ fixed-frequency ultrasonic energy at $1800 \mathrm{~W}$ electric power. As shown in Figure $5 \mathrm{a}$, the $\alpha$-Mg grains are refined to some degree in the center of the billet compared with Figure 4a. However, grain size in $1 / 2 \mathrm{R}$ and the edge of the billet have no large difference. Some coarse dendrites are removed.
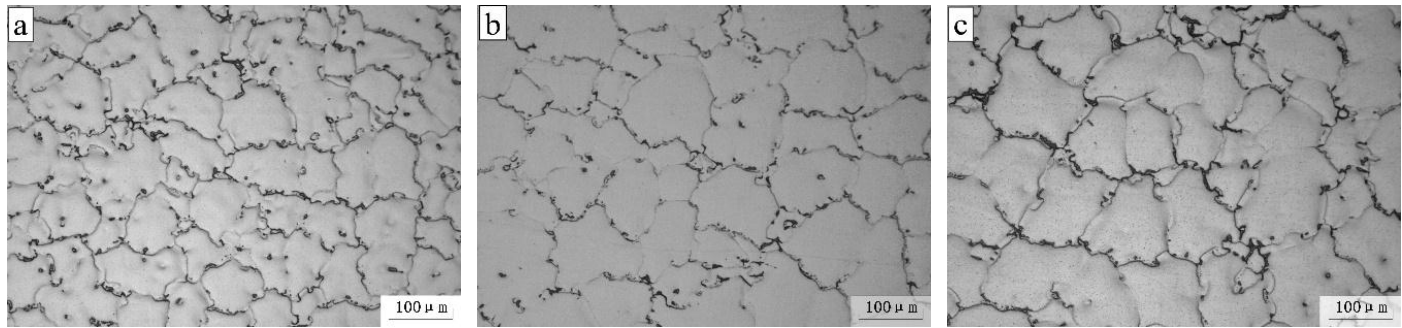

Figure 5. Microstructures of as-cast ZK60 alloy treated by fixed-frequency ultrasonic vibration at (a) center; (b) 1/2R; (c) edge position of billet.

Figure 6 presents the as-cast microstructures of the ZK60 alloy isothermally treated by ultrasonic energy with $20 \pm 1 \mathrm{kHz}$ variable-frequency at $1800 \mathrm{~W}$ electric power. There are obvious changes of grain size in the whole billet. Coarse dendrites almost disappeared and globular $\alpha$-Mg grains become dominant. The microstructures of ZK60 alloy consisted of homogeneous grains.
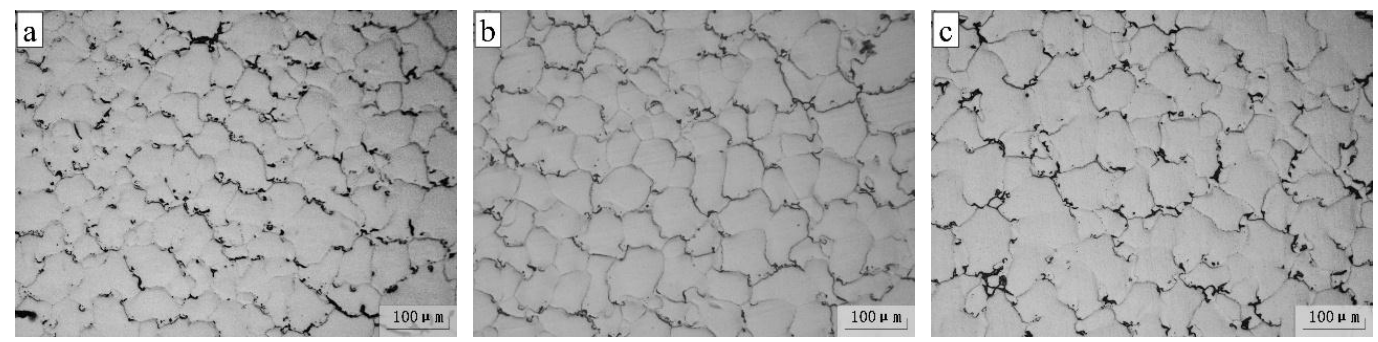

Figure 6. Microstructures of as-cast ZK60 alloy treated by variable-frequency ultrasonic vibration at (a) center; (b) 1/2R; (c) edge position of billet.

Figure 7 indicates the average grain size of ZK60 alloy with different ultrasonic processes. It is obvious that ultrasonication can refine the grain to different degrees in different positions of a billet, and variable-frequency ultrasound reveals its strong power in grain refinement. Fixed-frequency ultrasonication shows lower efficiency on grain refinement, the grain size decrease from $168 \pm 8 \mu \mathrm{m}$ to $112 \pm 7 \mu \mathrm{m}, 201 \pm 8 \mu \mathrm{m}$ to $149 \pm 9 \mu \mathrm{m}$, and $186 \pm 10 \mu \mathrm{m}$ to $165 \pm 12 \mu \mathrm{m}$ at the position center, $1 / 2 R$, and edge of billet, respectively. The variable-frequency ultrasound can not only refine the microstructures of the billets more effectively from edge to center, but it can also make the 
microstructures much more uniform than fixed-frequency ultrasound. The grain sizes are dramatically decreased to $70 \pm 4 \mu \mathrm{m}$ (center), $78 \pm 5 \mu \mathrm{m}(1 / 2 \mathrm{R})$, and $101 \pm 7 \mu \mathrm{m}$ (edge).

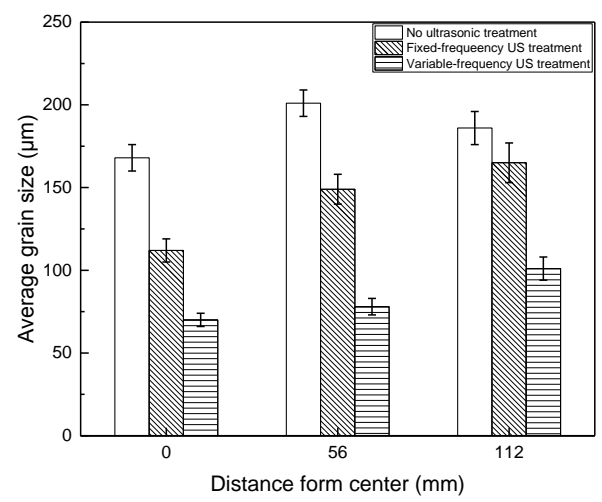

Figure 7. Average grain size of ZK60 alloys with different ultrasonic treatments.

The effects of ultrasonic vibration on grain refinement attribute to cavitation-enhanced heterogeneous nucleation and dendrite fragmentation. At the beginning of solidification, the temperature between pouring temperature and the liquidus temperature of the alloy, cavitation-enhanced heterogeneous nucleation was the main effect of ultrasonic grain refinement, since dendrite fragmentation would not be possible at those temperatures due to solidification having not started yet. When at a temperature below the liquidus temperature, acoustic streaming started to work in the melt, which can lead to dendrite fragmentation and disturbance of nuclei. These two simultaneously existed mechanisms generate a high density of nuclei in melt, which can lead to the development of a multitude of globular grains with small grain size.

Owing to the acoustic pressure playing a significant role in grain refinement, in order to study the ultrasonic field propagation, numerical simulations were carried out. The acoustic pressure $p$ can be obtained by solving the wave equation as

$$
\frac{1}{\rho c^{2}} \frac{\partial^{2} p}{\partial t^{2}}-\nabla \cdot\left(\frac{1}{\rho}\left(\nabla p+\frac{\delta}{\rho c^{2}} \frac{\partial(\nabla p)}{\partial t}\right)\right)
$$

where $\rho$ is the density of the melt, $c$ is the speed of the sound in the melt, $\delta$ is a measure of the acoustic diffusivity. With the time harmonic assumption, a solution of the form is obtained as

$$
P(r, z, t)=p(r, z) e^{i \omega t}
$$

where $\omega$ is the angular frequency.

The intensity distribution $I(r, z)$ can be obtained as

$$
I(r, z)=\frac{p^{2}(r, z)}{2 \rho c}
$$

The wave equation was solved by the finite element method. The following boundary conditions are obtained (as shown in Figure 8a):

(1) $\quad p=0$ at the liquid-air interfaces corresponding to a total reflection condition as soft walls;

(2) $\partial p / \partial n=0$ at the side walls of the horn which represents hard walls;

(3) $\quad p=p_{0} \sin \left(2 \pi\left(f_{0}+\sin \left(2 \pi f_{1} t\right)\right) t\right)$ at the horn tip, where $p_{0}$ is the amplitude of the wave, $f_{0}$ is the initial frequency of the wave, $f_{1}$ is the changing frequency of wave frequency;

(4) $1 / \rho(\partial p / \partial n)+i \omega p / Z=0$ at the walls of the crystallizer and liquid cave which represents the impedance boundary condition and $Z$ is the acoustic input impedance of the external. 
Table 2 shows the material properties and some critical parameters used in the simulation.

Table 2. Material properties and some critical model parameters.

\begin{tabular}{ccc}
\hline Name & Value & Description \\
\hline$\rho$ & $1820 \mathrm{~kg} / \mathrm{m}^{3}$ & Density of magnesium alloy \\
$c$ & $4000 \mathrm{~m} / \mathrm{s}$ & Speed of sound in magnesium alloy \\
$\delta$ & $0.0279 \mathrm{~dB} / \mathrm{cm}$ & Attenuation coefficient \\
$f_{0}$ & $20 \mathrm{kHz}$ & Initial frequency of the wave \\
$f_{1}$ & $200 \mathrm{~Hz}$ & Changing frequency of wave frequency \\
$p_{0}$ & $3.2 \times 10^{6} \mathrm{~Pa}$ & Source pressure amplitude \\
$Z$ & $4.2 \times 10^{7} \mathrm{~Pa} \cdot \mathrm{s} / \mathrm{m}$ & Acoustic input impedance \\
\hline
\end{tabular}

Figure 8 shows the acoustic pressure of two ultrasonic vibration model at positions A, B, and C of the liquid cave. It is noticed that the variable-frequency ultrasonic field has higher acoustic pressure than fixed-frequency ultrasonic field. Average acoustic pressure at position A is much higher than B and $C$ in both acoustic fields. These differences lead to different refinement efficiencies.
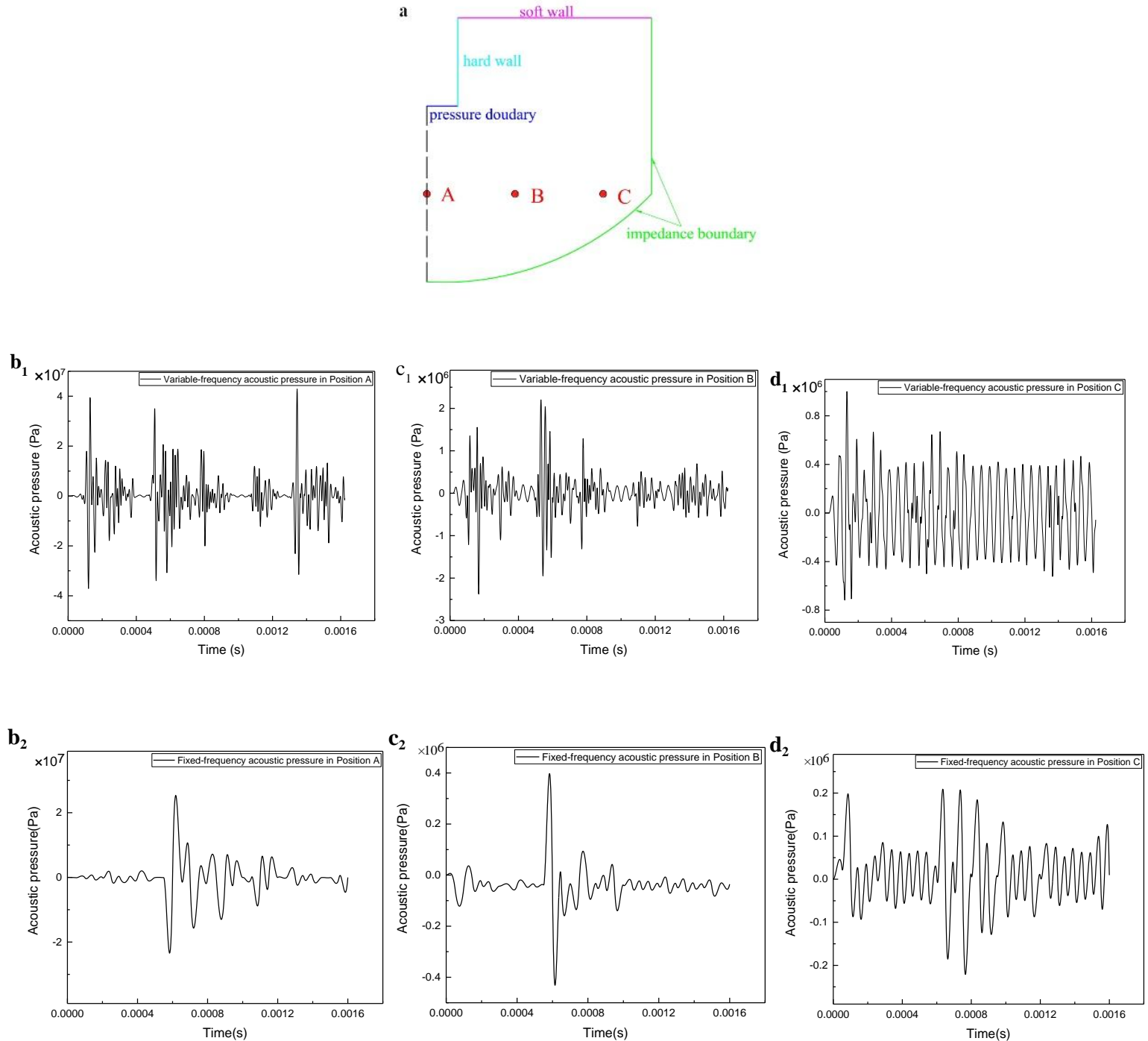

Figure 8. Variable-frequency acoustic pressure at position $A\left(b_{1}\right)$; position B $\left(\mathbf{c}_{1}\right)$; and position $C$ $\left(\mathbf{d}_{\mathbf{1}}\right)$ and fixed-frequency acoustic pressure at position A $\left(\mathbf{b}_{\mathbf{2}}\right)$; position B $\left(\mathbf{c}_{\mathbf{2}}\right)$; and position C $\left(\mathbf{d}_{\mathbf{2}}\right)$. (a) Boundary conditions. 
The different results of grain refinement effect among center, 1/2R, and edge (seen in Figures 4-6) could be ascribed to the sound attenuation in melt. The acoustic intensity decreases following the increase of acoustic propagation distance. Sound intensity $(I)$ along the propagation distance $(x)$ in a melt, according to expression (5):

$$
I=I_{0} e^{-2 \alpha x}
$$

where $\alpha$ is attenuation coefficient in melt. This attenuation coefficient is heavily depending on the viscosity and thermal conductivity of the melt. Thus, the sound attenuation cannot be neglected in large diameter casting. On one hand, the viscosity at edge of billet is higher than the center due to cooling water in crystallizer, leading to the increase of attenuation coefficient $(\alpha)$, so acoustic intensity decreases heavily at the edge of the liquid cave. On the other hand, according to the results of numerical simulation (seen in Figure 8), the average acoustic pressure $(p)$ at edge and 1/2R of the liquid cave is lower than center, meaning the sound intensity $(I)$ is lower at edge and $1 / 2 \mathrm{R}$ of liquid cave according to Equation (4). Thus, the grain refinement effect is weakened in edge and $1 / 2 \mathrm{R}$.

Based on the earlier discussion, the grain refinement efficiency strongly depends on acoustic cavitation and streaming produced by cavitation bubbles. There is more than one ultrasonic wave with different frequencies in melt generated from a variable-frequency ultrasonic source. These sound waves superpose with each other and affect acoustic pressure distribution, as seen in Figure 8. The compositive wave brings higher acoustic pressure compared with fixed-frequency ultrasound. $\mathrm{Xi}$ et al. have demonstrated that the cavitation bubble trajectory depends on the acoustic pressure amplitude and the initial bubble size: an increase of pressure amplitude can increase bubbles' sizes [27]. Therefore, higher acoustic pressure brings bigger cavitation bulbs, which can strengthen the cavitation effect. Assume that the cavitation bulbs' collapse process is adiathermic, the highest temperature $\left(T_{(\max )}\right)$ and the highest pressure $\left(P_{(\max )}\right)$ when a cavitation bulb collapsed is obtained as [28]:

$$
\begin{gathered}
P_{(\max )}=p_{i}\left[p_{a}(\gamma-1) / p_{v}\right]^{\gamma(\gamma-1)} \\
T_{(\max )}=T_{\min }\left[p_{a}(\gamma-1) / p_{v}\right]
\end{gathered}
$$

where $T_{\min }$ is the temperature of melt, $p_{a}$ is the extra pressure out of the bulb, $p_{i}$ is the initial pressure in the bulb, $p_{v}$ is the equilibrium vapor pressure, $\gamma$ is the specific heat capacity. In ultrasonic melt treatment process, the $p_{a}$ relies on the acoustic pressure amplitude. According to Equation (6), the highest pressure $\left(P_{(\max )}\right)$ and $p_{a}$ have an exponential relation, which is that the highest pressure $\left(P_{(\max )}\right)$ increases following the increase of acoustic pressure. Hence, associated with results shown in Figure 8 , the variable-frequency acoustic vibration can lead to higher pressure when a cavitation bulb collapsed than fixed-frequency ultrasound. Consequently, higher impact force is introduced, which reinforce the acoustic streaming effect and dendrite fragmentation phenomenon. Equation (7) shows a linear relation between the highest temperature $\left(T_{(\max )}\right)$ and the $p_{a}$. The highest temperature $\left(T_{(\max )}\right)$ increases with the increase of acoustic pressure. Thus, when ZK60 magnesium alloy melt was treated by variable-frequency ultrasound, a higher degree of energy fluctuation occurred in the melt, which can lead to reinforcement of cavitation-enhanced heterogeneous nucleation phenomenon. Vanhille et al. have demonstrated that cavitation bubbles appear easily at high acoustic amplitude [29]. Moreover, Feng et al. have reported that a multi-frequency sonication field can increase the number of cavitation bulbs [30]. Therefore, these high acoustic pressure different sound waves with different frequencies can produce a large volume concentration of bubbles, which could enhance the cavitation effect, increasing grain refinement efficiency. Besides, higher acoustic pressure brought by variable-frequency ultrasound can also reduce the negative impact of sound attenuation.

Figure 9 presents the $\beta$-phase morphology images of billet with different sonication by SEM. The coarse $\beta-\mathrm{MgZn}$ phases appear on the grain boundary with the shape of nets in no ultrasonic treated casting (seen in Figure 9a). While reticular $\beta-\mathrm{MgZn}$ phases are broken when the fixed-frequency ultrasonic field was applied, and some spherical $\beta-\mathrm{MgZn}$ phases are observed (as shown in Figure $9 \mathrm{~b}$ ). When the 
melt was treated by variable-frequency ultrasonic energy, the morphology of $\beta-\mathrm{MgZn}$ phases shrank. It is obvious that the ultrasonic field can change the distribution and morphology of $\beta$-phase in ZK60 alloy.
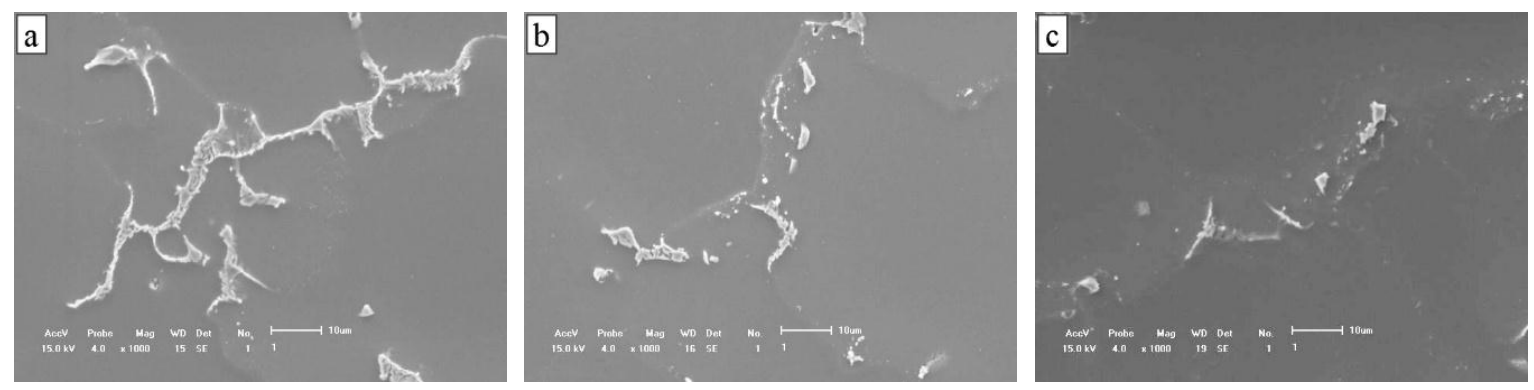

Figure 9. Scanning electronic microscope (SEM) images: (a) no ultrasonic treatment; (b) fixed-frequency ultrasonic treatment; (c) variable-frequency ultrasonic treatment.

The mechanism of shape change of $\beta$-phase on ZK60 alloy is not well understood, and available references are very scarce. We think the possible mechanism can be explained as follows: when the cavitation bulbs collapsed under the acoustic field, a strong impact force was introduced in the magnesium melt, which was likely to fracture the reticular $\beta-\mathrm{MgZn}$ phases, resulting in tinier $\mathrm{MgZn}$ phases on the grain boundary. According to previous discussion, variable-frequency acoustic fields can produce higher impact force. Therefore, the $\beta-\mathrm{MgZn}$ phases become tinier under variable-frequency acoustic field.

\subsection{Mechanical Properties and Segregation}

The mechanical properties of the ZK60 Mg alloy billets cast by different processes were examined, with the results shown in Figures 10-12. One can notice that ultrasonication can improve billets' yield strength and variable-frequency ultrasound has higher efficiency. Figure 11 demonstrates the ultimate tensile strength (UTS) at different positions of billet with different ultrasonic treatments. It is clear that the UTS of the billets cast by the conventional DC process were lowest. The strength values are $235 \pm 8 \mathrm{MPa}, 221 \pm 6 \mathrm{MPa}$, and $210 \pm 7 \mathrm{MPa}$ at the positions of center, 1/2R, and edge in billet respectively. The UTS increase to $251 \pm 7 \mathrm{MPa}, 241 \pm 8 \mathrm{MPa}$, and $217 \pm 6 \mathrm{MPa}$ when fixed-frequency ultrasound played its role during semi-continuous casting, showing good improvement in center and $1 / 2 \mathrm{R}$ but poor promoting in edge. While variable-frequency acoustic energy can observably promote billets' UTS, which increase to $280 \pm 8 \mathrm{MPa}$ (center), $263 \pm 6 \mathrm{MPa}(1 / 2 \mathrm{R})$, and $245 \pm 6 \mathrm{MPa}$ (edge). Meanwhile, the elongation is also largely promoted especially the melt was treated by variable-frequency ultrasound. For example, the elongation in center of the billet increase from $6.1 \%$ to $8.9 \%$ with variable-frequency ultrasound treatment, which is $45.9 \%$ higher than non-ultrasonic treated sample.

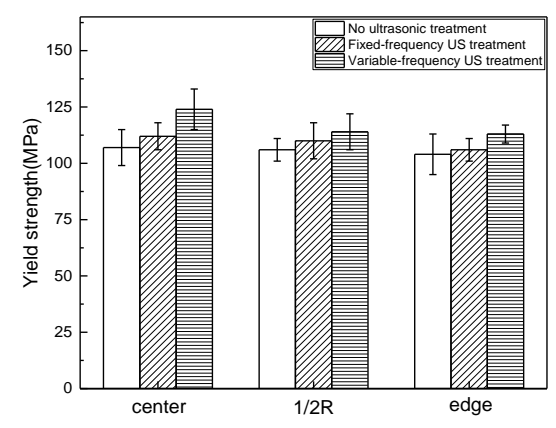

Figure 10. Yield strength of ZK60 alloy with different ultrasonic treatments. 


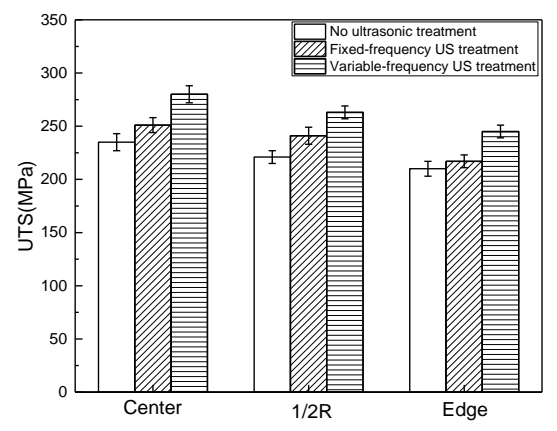

Figure 11. Ultimate tensile strength of ZK60 alloy with different ultrasonic treatments.

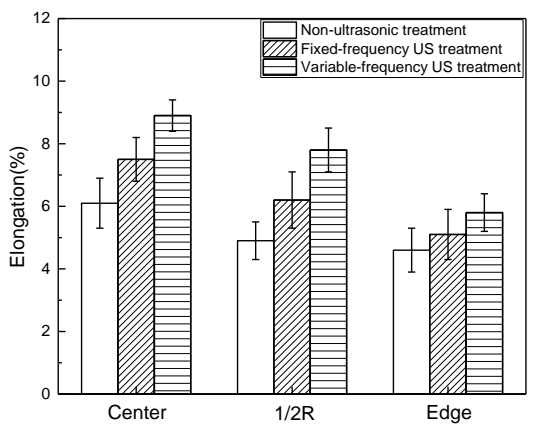

Figure 12. Elongation of ZK60 alloy with different ultrasonic treatments.

The yield strength of as-cast ZK60 alloy is improved by variable-frequency, as shown in Figure 10. According to the well-known Hall-Petch relation, the yield stress depends on the grain size as follows:

$$
\sigma_{y}=\sigma_{0}+k d^{-1 / 2}
$$

where the friction stress $\sigma_{0}=88 \mathrm{MPa}$ [31] and strengthening coefficient $k=316 \mathrm{MPa}$ [32]. By using Equation (8) and the measured grain size in Figure 6, it is in a certain agreement for the calculated and experimental yield strength in this work.

The UTS and elongation of as-cast ZK60 alloy are remarkably improved by ultrasonic treatment, especially with variable-frequency treatment, as shown in Figures 11 and 12. Mechanical properties of ZK60 alloy depend on several factors. The precipitated phase morphology and distribution should be firstly considered for UTS promotion. It is well known that the MgZn phase is the main strengthening phase in ZK60 alloys [33]. Ultrasonic vibration could affect the distribution and morphology of MgZn phase in ZK60 alloy, as shown in Figure 9. The MgZn phases become tiny and globular by acoustic vibration, particularly under variable-frequency ultrasound's influence. These tiny $\mathrm{MgZn}$ phases evenly distribute on the grain boundary, increasing the UTS of as-cast ZK60 alloy. Besides, the refinement grain also needs to be considered. The UTS is exponentially dependent to the grain size [31], which means that UTS increase with the decreasing of grain size. Thereby, the increase of UTS and elongation in this work can be attributed to the combined effect of the tiny MgZn phase distribution and the globular and small size of grain.

Figure 13 indicates the segregation rate of main elements with different ultrasonic treatments. The $\mathrm{Zr}$ has less segregation rate than $\mathrm{Zn}$. It is noticed that ultrasonic vibration can reduce the segregation of the billet and the variable-frequency US treatment has a higher efficiency than fixed-frequency US treatment. The maximum segregation rate of $\mathrm{Zr}$ reduces from $2.09 \%$ to $0.79 \%$ and for $\mathrm{Zn}$ reduces from $25.17 \%$ to $6.97 \%$. 
(a)

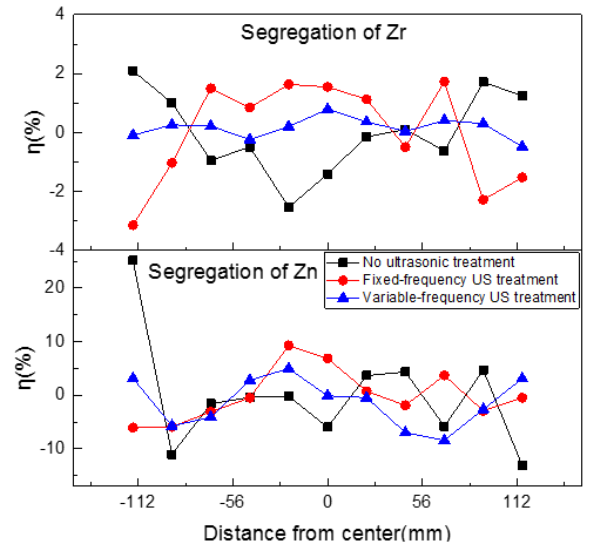

Figure 13. Segregation rate of ZK60 alloy with different ultrasonic treatments: (a) Zr; (b) Zn.

The acoustic streaming plays the primary role in decreasing segregation. According to the Eckart acoustic steaming theory [34-36], the maximum axial velocity should be proportional to the sound intensity. Associating with the results of simulation, the variable-frequency ultrasonic treatment is able to bring higher sound intensity, which can enhance the acoustic steaming. Therefore, variable-frequency US treatment has a higher degree of decrease of segregation rate.

\section{Conclusions}

In this study, traditional ultrasonic technology and a variable-frequency ultrasonic technology were used in large diameter semi-continuous casting of ZK60 alloy, to evaluate the influence of ultrasonic treatment in microstructure and mechanical properties. In what concerns grain refinement and mechanical properties improvement, the results show that:

(1) Ultrasonic treatment is a clean, eco-friendly, and efficient physical technology that can be recognized as a method to control the size and morphology of $\alpha-\mathrm{Mg}$ grains and distribution of $\beta-M g Z n$ phases;

(2) The different refinement efficiencies appearing in different districts of the billet are attributed to the sound attenuation in melt and refinement efficiency reducing follow the increase of distance from ultrasonic radiator;

(3) Variable-frequency ultrasound shows its strong power in grain refinement compared with traditional fixed-frequency ultrasound. Globular $\alpha$-Mg grains with $70 \mu \mathrm{m}$ (center), $78 \mu \mathrm{m}(1 / 2 \mathrm{R})$, and $101 \mu \mathrm{m}$ (edge) are obtained when variable-frequency ultrasound was used;

(4) Microstructure refinement was followed by promotion in mechanical properties. The UTS increase from 235 to $280 \mathrm{MPa}$ (center), 221 to $263 \mathrm{MPa}(1 / 2 \mathrm{R})$, and 210 to $245 \mathrm{MPa}$ (edge) and elongation from $6.1 \%$ to $8.9 \%$ (center), $4.9 \%$ to $7.8 \%(1 / 2 \mathrm{R})$, and $4.6 \%$ to $5.8 \%$ (edge), respectively, compared with non-ultrasonic treatment;

(5) The variable-frequency acoustic field improves refinement effects by enhancing cavitation-enhanced heterogeneous nucleation and dendrite fragmentation effects.

Acknowledgments: This research was financially supported by the National Key Research and Development Program of China (Grant Nos. 2016YFB0301101, 2016YFB0301104) and the National Basic Research Program of China (Grant No. 2013CB632203).

Author Contributions: Xingrui Chen and Qichi Le conceived and designed the experiments; Xingrui Chen, Qichi Le and Xibo Wang performed the experiments; Qiyu Liao and Chaoyang Chu analyzed the data; Qiyu Liao contributed reagents/materials/analysis tools; Xingrui Chen wrote the paper.

Conflicts of Interest: The authors declare no conflict of interest. 


\section{References}

1. Staiger, M.P.; Pietak, A.M.; Huadmai, J.; Dias, G. Magnesium and its alloys as orthopedic biomaterials: A review. Biomaterials 2006, 27, 1728-1734. [CrossRef] [PubMed]

2. Ali, Y.H.; Qiu, D.; Jiang, B.; Pan, F.S.; Zhang, M.X. Current research progress in grain refinement of cast magnesium alloys: A review article. J. Alloy. Compd. 2015, 619, 639-651. [CrossRef]

3. Jin, S.L.; Li, Y.W.; Li, Y.B.; Zhao, L.; Liu, X.H.; Liu, J.; Li, Z.Y. Modified directed melt nitridation of pure aluminum block using magnesium as an external dopant. J. Mater. Sci. 2007, 42, 7311-7315. [CrossRef]

4. Gupta, N.; Luong, D.D.; Cho, K. Magnesium matrix composite foams-density, mechanical properties, and applications. Metals 2012, 2, 238-252. [CrossRef]

5. Dieringa, H. Influence of cryogenic temperatures on the microstructure and mechanical properties of magnesium alloys: A review. Metals 2017, 7, 38. [CrossRef]

6. Huot, J.; Skryabina, N.Y.; Fruchart, D. Application of severe plastic deformation techniques to magnesium for enhanced hydrogen sorption properties. Metals 2012, 2, 329-343. [CrossRef]

7. Roncevic, I.S.; Metikos-Hukovic, M.; Buzuk, M.; Vladislavic, N. Effective and environmentally friendly nickel coating on the magnesium alloy. Metals 2016, 6, 312 .

8. Wolff, M.; Schaper, J.G.; Suckert, M.R.; Dahms, M.; Feyerabend, F.; Ebel, T.; Willumeit-Romer, R.; Klassen, T. Metal injection molding (MIM) of magnesium and its alloys. Metals 2016, 6, 118. [CrossRef]

9. Zhang, W.Q.; Xiao, W.L.; Wang, F.; Ma, C.L. Development of heat resistant Mg-Zn-Al-based magnesium alloys by addition of La and Ca: Microstructure and tensile properties. J. Alloy. Compd. 2016, 684, 8-14. [CrossRef]

10. Liu, X.; Zhang, Z.Q.; Le, Q.C.; Bao, L. The effects of ZnO particles on the grain refinement and mechanical properties of AZ31 magnesium alloys. Trans. Indian Inst. Met. 2016, 69, 1911-1918. [CrossRef]

11. Yang, P.; Zhao, Z.; Ren, X.P.; Huang, S.D. Microstructure, textures and deformation behaviors of fine-grained magnesium alloy AZ31. J. Mater. Sci. Technol. 2005, 21, 331-337.

12. Prasad, A.; Uggowitzer, P.J.; Shi, Z.; Atrens, A. Production of high purity magnesium alloys by melt purification with Zr. Adv. Eng. Mater. 2012, 14, 477-490. [CrossRef]

13. Nogita, K.; Dahle, A.K. Effects of boron on eutectic modification of hypoeutectic Al-Si alloys. Scr. Mater. 2003, 48, 307-313. [CrossRef]

14. Cao, P.; Qian, M.; StJohn, D.H.; Frost, M.T. Uptake of iron and its effect on grain refinement of pure magnesium by zirconium. Mater. Sci. Technol. 2004, 20, 585-592. [CrossRef]

15. Cheng, R.J.; Pan, F.S.; Jiang, S.; Li, C.; Jiang, B.; Jiang, X.Q. Effect of Sr addition on the grain refinement of AZ31 magnesium alloys. Prog. Nat. Sci. 2013, 23, 7-12. [CrossRef]

16. Guo, S.J.; Le, Q.C.; Zhao, Z.H.; Wang, Z.J.; Cui, H.Z. Microstructural refinement of DC cast AZ80 Mg billets by low frequency electromagnetic vibration. Mater. Sci. Eng. A 2005, 404, 323-329. [CrossRef]

17. Ramirez, A.; Qian, M.; Davis, B.; Wilks, T.; StJohn, D.H. Potency of high-intensity ultrasonic treatment for grain refinement of magnesium alloys. Scr. Mater. 2008, 59, 19-22. [CrossRef]

18. Eskin, G.I. Broad prospects for commercial application of the ultrasonic (cavitation) melt treatment of light alloys. Ultrason. Sonochem. 2001, 8, 319-325. [CrossRef]

19. Rashad, M.M. Magnetic properties of nanocrystalline magnesium ferrite by co-precipitation assisted with ultrasound irradiation. J. Mater. Sci. 2007, 42, 5248-5255. [CrossRef]

20. Lee, Y.C.; Dahle, A.K.; Stjohn, D.H. The role of solute in grain refinement of magnesium. Metall. Mater. Trans. A 2000, 31, 2895-2906. [CrossRef]

21. Liu, X.; Zhang, Z.Q.; Hu, W.Y.; Le, Q.C.; Bao, L.; Cui, J.Z.; Jiang, J.J. Study on hydrogen removal of AZ91 alloys using ultrasonic argon degassing process. Ultrason. Sonochem. 2015, 26, 73-80. [CrossRef] [PubMed]

22. Hu, Z.; Li, X.; Yan, H.; Wu, X.Q.; Qun, H.; Lin, J.W. Effects of ultrasonic vibration on microstructure evolution and elevated-temperature mechanical properties of hot-extruded Mg-6Al-0.8Zn-2.0Sm wrought magnesium alloys. J. Alloy. Compd. 2016, 685, 58-64. [CrossRef]

23. Xue, H.S.; Li, D.; Yang, G.; Zhang, D.F. Ultrasonic effects on microstructure evolution and mechanical properties of AZ80 magnesium alloy. Rare Met. Mater. Eng. 2016, 45, 1401-1405.

24. Fang, X.; Wu, S.; Lü, S.; Wang, J.; Yang, X. Microstructure evolution and mechanical properties of quasicrystal-reinforced Mg-Zn-Y alloy subjected to ultrasonic vibration. Mater. Sci. Eng. A 2016, 679, 372-378. [CrossRef] 
25. Gao, D.; Li, Z.; Han, Q.; Zhai, Q. Effect of ultrasonic power on microstructure and mechanical properties of AZ91 alloy. Mater. Sci. Eng. A 2009, 502, 2-5. [CrossRef]

26. Eskin, G.I. Principles of ultrasonic treatment: Application for light alloys melts. Adv. Perform. Mater. 1997, 4, 223-232. [CrossRef]

27. Xi, X.; Cegla, F.B.; Lowe, M.; Thiemann, A.; Nowak, T.; Mettin, R.; Holsteyns, F.; Lippert, A. Study on the bubble transport mechanism in an acoustic standing wave field. Ultrasonics 2011, 51, 1014-1025. [CrossRef] [PubMed]

28. Rae, J.; Ashokkumar, M.; Eulaerts, O.; von Sonntag, C.; Reisse, J.; Grieser, F. Estimation of ultrasound induced cavitation bubble temperatures in aqueous solutions. Ultrason. Sonochem. 2005, 12, 325-329. [CrossRef] [PubMed]

29. Vanhille, C.; Campos-Pozuelo, C. Acoustic cavitation mechanism: A nonlinear model. Ultrason. Sonochem. 2012, 19, 217-220. [CrossRef] [PubMed]

30. Feng, R.; Zhao, Y.Y.; Zhu, C.P.; Mason, T.J. Enhancement of ultrasonic cavitation yield by multi-frequency sonication. Ultrason. Sonochem. 2002, 9, 231-236. [CrossRef]

31. Lee, C.D. Effect of grain size on the tensile properties of magnesium alloy. Mater. Sci. Eng. A 2007, 459, 355-360. [CrossRef]

32. Ma, C.; Liu, M.; Wu, G.; Ding, W.; Zhu, Y. Tensile properties of extruded ZK60-RE alloys. Mater. Sci. Eng. A 2003, 349, 207-212. [CrossRef]

33. Maeng, D.Y.; Kim, T.S.; Lee, J.H.; Hong, S.J.; Seo, S.K.; Chun, B.S. Microstructure and strength of rapidly solidified and extruded Mg-Zn alloys. Scr. Mater. 2000, 43, 385-389. [CrossRef]

34. Madelin, G.; Grucker, D.; Franconi, J.M.; Thiaudiere, E. Magnetic resonance imaging of acoustic streaming: Absorption coefficient and acoustic field shape estimation. Ultrasonics 2006, 44, 272-278. [CrossRef] [PubMed]

35. Frenkel, V.; Gurka, R.; Liberzon, A.; Shavit, U.; Kimmel, E. Preliminary investigations of ultrasound induced acoustic streaming using particle image velocimetry. Ultrasonics 2001, 39, 153-156. [CrossRef]

36. Frampton, K.D.; Minor, K.; Martin, S. Acoustic streaming in micro-scale cylindrical channels. Appl. Acoust. 2004, 65, 1121-1129. [CrossRef]

(c) 2017 by the authors. Licensee MDPI, Basel, Switzerland. This article is an open access article distributed under the terms and conditions of the Creative Commons Attribution (CC BY) license (http:/ / creativecommons.org/licenses/by/4.0/). 